\title{
Rook- en alcoholspecifieke opvoeding
}

\author{
De huidige stand van zaken op het gebied van onderzoek en \\ preventie
}

Haske van der Vorst, Evelien Vermeulen en Regina J. J. M. van den Eijnden

\begin{abstract}
SAMENVATTING
Interventies die gericht zijn op gezinnen zijn effectiever in het uitstellen en verminderen van roken en alcoholgebruik bij adolescenten dan interventies die gericht zijn op leerlingen. Het effect van dergelijke gezinsprogramma's is vaak echter klein, mogelijk ten gevolge van de beperkte integratie van wetenschappelijk kennis over effectieve rook- en alcoholspecifieke opvoedingsaspecten. Wij adviseren om binnen bestaande gezinsgerichte interventies beter gebruik te maken van de kennis betreffende effectieve rook- en alcoholspecifieke opvoeding. Onderzoek laat namelijk zien dat rook- en alcoholspecifieke opvoeding bijdraagt aan het uitstellen en verminderen van roken en alcoholgebruik bij adolescenten. Op basis van de huidige wetenschappelijke inzichten zouden we ouders de volgende adviezen willen geven: niet of zo min mogelijk in het bijzijn van de kinderen roken of drinken, een anti-rook en anti-alcoholnorm uitdragen en zo nu en dan (niet te vaak) een constructief gesprek met de kinderen over alcoholgebruik en roken voeren. Met betrekking tot alcoholgebruik geldt daarnaast dat ouders het alcoholgebruik van hun kinderen zouden moeten verbieden en de beschikbaarheid van alcohol thuis zouden moeten beperken.
\end{abstract}

\section{Inleiding}

Ouders spelen een belangrijke rol in de ontwikkeling van alcohol- en rookgedrag van jongeren.

Een recente meta-analyse naar gezinsgerichte alcoholinterventies laat zien dat dergelijke interventies over het algemeen succesvol zijn in het uitstellen van beginnen met alcoholgebruik, zelfs na 48 maanden, en het verminderen van de frequentie van

Dr. H. van der Vorst, is als onderzoeker werkzaam binnen het Behavioural Science Institute van de Radboud Universiteit Nijmegen. Postbus 9104, 6500 HE Nijmegen. E-mail: H.vandervorst@pwo.ru.nl.

Ir. E. Vermeulen-Smit is als junior wetenschappelijk medewerker werkzaam op de afdeling epidemiologie van het Trimbos-instituut.

Dr. R. J. J. M. van den Eijnden is als universitair docent werkzaam op de afdeling Algemene Sociale Wetenschappen van de Universiteit Utrecht. 
alcoholgebruik (Smit, Verdurmen, Monshouwer, \& Smit, 2008). Gezinsgerichte interventies lijken ook effectief te zijn ter preventie van roken (Jackson \& Dickinson, 2006). Overzichtstudies bevestigen deze conclusies (o.a. Kumpfer, Alvarado, \& Whiteside, 2003). Zo concluderen Kumpfer en anderen (2003) dat gezinsgerichte interventies (welke zowel op de ouder als de adolescent gericht zijn) 2 tot 9 keer sterkere effecten bewerkstelligen dan kindgerichte interventies (bijv. via school, of het weerstaan van druk van leeftijdsgenoten). Ook het Nederlandse Preventieproject Alcoholgebruik Scholieren (PAS) blijkt het meest effectief te zijn in het reduceren van alcoholgebruik onder middelbare scholieren, als zowel adolescenten als ouders een programma over alcoholgebruik wordt aangeboden (Koning e.a., 2009). Er is dus voldoende empirisch bewijs dat gezinsgerichte interventies een belangrijke bijdrage kunnen leveren aan het verminderen van het alcoholgebruik en roken onder jongeren. Deze conclusie kan echter nog niet volledig bevestigd worden voor de Nederlandse situatie. Het middelengebruik van Amerikaanse en Nederlandse jongeren verschilt nogal, waardoor de gegevens uit effectonderzoek dat in de V.S. is uitgevoerd niet zomaar op de Nederlandse situatie van toepassing is. Bovendien zijn de bestaande gezinsgerichte interventies niet altijd gebaseerd op de huidige wetenschappelijke kennis omtrent rook- en alcoholspecifieke opvoeding.

De focus van het onderzoek naar de rol van ouders in de ontwikkeling van het alcoholgebruik en rookgedrag van jongeren is de afgelopen jaren verschoven van algemene opvoeding naar alcohol- en rookspecifieke opvoeding (o.a. Harakeh, Scholte, De Vries, \& Engels, 2005; Van der Vorst, Engels, Meeus, Dekovic, \& Van Leeuwe, 2005). Bij algemene opvoeding lag de nadruk op de mate waarin ouders (emotionele) steun aan hun kinderen bieden en de mate waarin ouders toezicht op hun kinderen houden (de controledimensie). Deze studies bespreken echter niet hoe ouders specifiek met het rook- en drinkgedrag van hun kinderen om kunnen gaan. Ouders in Nederland bijvoorbeeld communiceren over het algemeen open met hun kinderen, zijn gericht op het goed willen houden van hun relatie met hun kind, maar kunnen tegelijkertijd het onderwerp alcohol of roken vermijden. Vandaar dat er steeds meer belangstelling is voor alcohol- en rookspecifieke opvoeding is, zowel bij onderzoekers als bij preventiemedewerkers.

De vraag is nu welke rook- en alcoholspecifieke opvoedingskenmerken effectief zijn en aanknopingspunten bieden voor preventieve interventies. In dit artikel geven we een overzicht van het huidige onderzoek naar de invloed van alcohol- en rookspecifieke opvoeding op het alcoholgebruik en rookgedrag van jongeren. Achtereenvolgens zullen de volgende rook- en alcoholspecifieke opvoedkenmerken besproken worden: normen, regels, communicatie, voorbeeldgedrag van ouders ten aanzien van middelengebruik en beschikbaarheid van alcohol en rookwaren. Vervolgens wordt nagegaan in hoeverre bestaande gezinsgerichte interventies gebruikmaken van wetenschappelijke bewijs voor de effectiviteit van alcohol- en rookspecifieke opvoeding. 


\section{Effectiviteit van alcohol- en rookspecifieke opvoedingskenmerken}

\section{Normen ten aanzien van roken en alcoholgebruik}

Ouders hebben bepaalde normen of attitudes die de basis vormen voor hun opvoeding. Het uiten van deze normen is van invloed op het gedrag van hun kinderen. Ouders hebben ook normen of meningen over alcoholgebruik en roken van hun adolescente kinderen. Gezondheidsnormen ten aanzien van roken en alcohol kunnen heel verschillend zijn. Dat wil zeggen, in Nederland is de norm rond alcoholgebruik steeds meer 'vanaf 16 jaar' terwijl bij roken 'nooit' de norm is. Daarnaast verschilt de ervaren ernst van roken en het drinken van alcohol tijdens de puberteit sterk tussen ouders (Verdurmen, Smit, Van Dorsselaer, Monshouwer, \& Schulten, 2008).

In veel westerse landen keuren ouders het af als kinderen en adolescenten alcohol drinken. Deze afkeuring door ouders is gerelateerd aan minder alcoholgebruik (Bahr, Hoffmann, \& Yang, 2005) en minder bingedrinken onder jongeren. Ook een lagere frequentie van (zwaar) drinken en dronkenschap bij jongeren lijken gerelateerd aan strikte normen ten aanzien van alcoholgebruik. Dit werd in andere studies echter niet altijd bevestigd. Over het geheel genomen lijkt er voldoende empirisch bewijs voor een sterke samenhang tussen normen van ouders over het alcoholgebruik van hun kinderen en het drinkgedrag van adolescenten. Bij roken is het empirisch bewijs nog eenduidiger: afkeurende normen van ouders ten aanzien van roken zijn gerelateerd aan het roken van minder sigaretten door jongeren (o.a. Bahr e.a., 2005). Het tonen van afkeuring ten aanzien van roken hangt ook samen met een lagere kans op beginnen met roken bij jongeren (Engels \& Willemsen, 2004).

\section{Het stellen van alcohol- en rookspecifieke regels}

De normen die ouders hebben over middelengebruik uiten zich vaak ook in de regels die ouders stellen ten aanzien van alcoholgebruik en roken van hun kinderen. Regels stellen is belangrijk bij het uitstellen en verminderen van alcoholgebruik (o.a. Van der Vorst, Vermulst, Meeus, Deković, \& Engels, 2009), maar minder duidelijk is of dit ook effectief is ter preventie van roken. Ten aanzien van alcoholgebruik laat zowel nationaal (o.a. Van der Vorst, Engels, Deković, Meeus, \& Vermulst, 2007) als internationaal onderzoek (Jackson, Henriksen, \& Dickinson, I999) zien dat het stellen van strikte regels een preventief effect heeft op zowel beginnen met alcoholgebruik als regelmatig en overmatig alcoholgebruik. Regels stellen zorgt er in de eerste plaats voor dat jongeren op een latere leeftijd beginnen met het drinken van alcohol (Van der Vorst e.a., 2007). Als adolescenten eenmaal een drinkpatroon hebben ontwikkeld, neemt de invloed van het stellen van strikte regels van ouders af. Echter de groei in de hoeveelheid alcohol die jongeren drinken, is minder sterk als ouders het alcoholgebruik verbieden dan wanneer zij dit toelaten (Van der Vorst e.a., 2009).

Ten aanzien van de effectiviteit van rookspecifieke (huis)regels laat de wetenschappelijke literatuur een inconsistent beeld zien. Volgens een aantal studies uit de V.S. kan het stellen van regels effectief zijn om roken bij jongeren te voorkomen, terwijl Nederlandse studies deze resultaten niet helemaal kunnen bevestigen. De meeste Nederlandse studies vonden geen (Den Exter Blokland, Hale, Meeus, \& Engels, 2006) of een zeer beperkt effect van regels ten aanzien van roken (o.a. Huver, Engels, \& De 
Vries, 2006;). Huver en collega's (2006) toonden aan dat roken totaal verbieden zelfs een averechts effect kan hebben: wanneer ouders hun kind verbieden te gaan roken lijkt dit de kans dat het kind gaat roken, te vergroten. Ook ten aanzien van huisregels lijkt er een tegenstelling te bestaan tussen studies uit de V.S. en Nederland. Enkele studies uit de V.S. impliceren dat het hanteren van huisregels ten aanzien van roken samenhangt met een lager risico op beginnen met roken bij jongeren. Huisregels ten aanzien van roken lijken echter niet van invloed te zijn op het rookgedrag van Nederlandse adolescenten. Deze verschillen in bevindingen kunnen mogelijk voortvloeien uit een verschil in meetinstrumenten, maar kunnen ook een verschil van de culturele context weerspiegelen (V.S. versus Nederland).

Sommige ouders maken de afspraak met hun kinderen dat zij nooit zullen roken of niet zullen roken tot een bepaalde leeftijd. De effecten van een dergelijke 'niet-roken afspraak' lijken echter niet overtuigend. Cross-sectionele studies geven aanwijzingen voor een mogelijk gunstig effect, maar deze effecten lijken longitudinaal niet bevestigd te worden (Den Exter Blokland e.a., 2006). In longitudinaal onderzoek bij iets oudere adolescenten zijn zelfs negatieve effecten gevonden van een niet-roken afspraak (Huver e.a., 2006).

Samengevat blijkt dat het stellen van regels effectief is bij het uitstellen en het verminderen van alcoholgebruik onder adolescenten. Bij roken zijn de effecten van regels nog niet eenduidig aangetoond. Nader longitudinaal onderzoek dient hier uitsluitsel over te geven.

\section{Rook- en alcoholspecifieke communicatie}

Verbale communicatie is de meest directe manier om alcohol- en rookspecifieke opvoeding op adolescenten over te brengen. Door bijvoorbeeld over roken te praten kunnen ouders hun huisregels aan hun kinderen uitleggen of de redenen opnoemen waarom ze beter niet kunnen roken (Chassin, Presson, Todd, Rose, \& Sherman, I998). Communicatie is echter een multidimensionele term. De vele facetten van communicatie, zoals de kwaliteit van de communicatie tussen ouders en kinderen, de frequentie van communicatie, communicatiestrategieën, en de inhoud van gesprekken, bemoeilijkt het trekken van heldere conclusies over wat wel en wat niet helpt in het voorkómen en reduceren van het alcoholgebruik en roken bij jongeren. De meeste studies naar communicatie richten zich op de frequentie van communicatie over alcoholgebruik en roken en een paar studies hebben de relatie tussen de kwaliteit van communicatie en middelengebruik van adolescenten onderzocht (Harakeh e.a., 2005; Van den Eijnden, Vet, Vermulst, \& Van de Mheen, 20Iо), terwijl andere dimensies, zoals de inhoud van de gesprekken en communicatiestrategieën onderbelicht zijn.

\section{Frequentie van communicatie}

Enkele Nederlandse cross-sectionele studies hebben een positief verband gevonden tussen de frequentie van communicatie over alcoholgebruik en het alcoholgebruik van jongeren (Van der Vorst e.a., 2005), terwijl andere studies uit de V.S. geen verband vonden tussen alcoholspecifieke communicatie en het alcoholgebruik van jongeren (Jackson e.a., I999). Een recente Nederlandse studie suggereert dat het positieve verband inhoudt dat de frequentie van communicatie over alcoholgebruik het drinken van 
jongeren stimuleert (het zogenaamde forbidden fruit effect) (Van der Vorst, Burk, \& Engels, in druk). Hoe vaker ouders over alcohol praatten, hoe meer de jongeren alcohol dronken. Dit effect leek vooral op te gaan voor jongens. Deze studie liet echter nog meer interessante sekseverschillen zien. Allereerst praatten ouders vaker met hun zonen dan met hun dochters over alcoholgebruik. De frequentie van communicatie bleef redelijk stabiel gedurende drie jaar voor jongens, maar nam significant af voor meisjes, mogelijk omdat ze het risico op (excessief) alcoholgebruik groter achtten bij hun zonen. Een recente longitudinale studie van Van den Eijnden en anderen (2010) liet echter geen effect zien van de frequentie van alcoholspecifieke communicatie op het alcoholgebruik van jongeren. Uit het bovenstaande kan geconcludeerd worden dat er bescheiden empirisch bewijs is voor het forbidden fruit effect. Hierbij kan echter niet uitgesloten worden dat een onbekende onderliggende factor zowel van invloed is op het praten van ouders over alcoholgebruik als op het alcoholgebruik van jongeren. Zo zou een sensatiebelust karakter van het kind er enerzijds voor kunnen zorgen dat ouders zich meer zorgen maken over hun kind en daardoor meer over alcoholgebruik praten, en anderzijds zou het ervoor kunnen zorgen dat jongeren ook daadwerkelijk meer drinken.

Volgens Harakeh en collega's geldt ook voor roken dat vaak praten over roken in het gezin gerelateerd is aan meer roken van jongeren (Harakeh, Scholte, Vermulst, De Vries, \& Engels, 20I0). Deze relatie lijkt zwakker te worden als de band tussen ouders en adolescenten goed is. De Leeuw en collega's bevestigen de directe positieve relatie tussen frequentie van rookspecifieke communicatie en roken bij adolescenten in een longitudinale studie (De Leeuw, Scholte, Harakeh, Van Leeuwe, \& Engels 2008). De positieve relatie tussen praten over roken en daadwerkelijk rookgedrag van jongeren wordt voor een deel verklaard door het feit dat ouders meer gaan praten over roken als zij ontdekken dat hun kinderen roken (o.a. Harakeh, Engels, Den Exter Blokland, Scholte, \& Vermulst, 2009). Bovendien is gebleken dat vaker over roken praten bij jongeren van dertien tot en met vijftien jaar het roken kan stimuleren (Harakeh e.a., 2009). Andere Nederlandse studies naar de frequentie van praten over roken suggereren dat de optimale frequentie om over roken te praten mogelijk afhankelijk is van de leeftijd van het kind. Met jonge adolescenten (onder de dertien jaar) over niet-roken praten, lijkt effectief te zijn. Op dertienjarige leeftijd lijkt dit echter een averechts effect te kunnen hebben en op zestienjarige leeftijd lijkt er geen impact meer te zijn (Den Exter Blokland e.a., 2006; Huver e.a., 2006).

\section{Kwaliteit van communicatie over roken en alcoholgebruik}

Volgens velen is een open communicatie belangrijk in het voorkomen en reduceren van allerlei probleemgedrag van jongeren waaronder alcoholgebruik en roken. Algemene communicatievoorwaarden zijn van belang, zoals respectvol met de ander omgaan, de ander serieus nemen, de ander op zijn of haar gemak stellen, luisteren naar wat de ander zegt en de ander de kans geven om bij te komen na een inspannend gesprek. Zo is het begeleiden van pubers bij hun denkproces belangrijk, zodat ze situaties logisch kunnen doordenken en bewust kunnen ervaren wat er in hen omgaat. Recent onderzoek bevestigt het belang van een goede ouder-kindcommunicatie als het gaat om alcoholgerelateerde onderwerpen (Van den Eijnden e.a., 2oro). De kwaliteit 
van de communicatie over alcoholgebruik tussen moeder en kind lijkt belangrijk in het verminderen van wekelijks alcoholgebruik. Onder kwaliteit van alcoholcommunicatie wordt bijvoorbeeld verstaan dat ouders en adolescenten interesse hebben in elkaars mening, gemakkelijk over alcoholgebruik kunnen praten en zich serieus genomen en begrepen voelen tijdens een gesprek over alcohol. Ook ten aanzien van roken lijkt de kwaliteit van ouder-kindcommunicatie van belang (De Leeuw e.a., 2008; Harakeh e.a., 20I0). Wanneer de kwaliteit van de communicatie over roken goed is, lijkt de frequentie van communicatie minder van invloed te zijn (Harakeh e.a., 2005). Ook een open discussie over waarom de ouder niet wil dat het kind rookt is gerelateerd aan minder roken bij jongeren (Chassin, e.a., I998).

Uit het bovenstaande blijkt dat de kwaliteit van communicatie tussen ouder en kind belangrijk is in het verminderen van roken en alcoholgebruik onder adolescenten. De paar longitudinale studies suggereren tevens dat als ouders vaak over alcohol of roken praten dit een averechts effect kan hebben: jongeren gaan dan soms juist meer drinken en roken. Hieruit zou geconcludeerd kunnen worden dat af en toe een goed gesprek over roken en alcohol goed is. Echter, om deze conclusie te mogen trekken is er meer onderzoek nodig waarbij ook andere aspecten van communicatie betrokken worden, zodat duidelijk wordt wat een kwalitatief goed gesprek (een constructief gesprek) over roken en alcohol precies inhoudt. Kortom er is meer onderzoek nodig naar de inhoud en sfeer van een gesprek, en naar de communicatiestrategieën die ouders en kinderen hanteren als zij samen over alcoholgebruik en roken praten.

\section{Voorbeeldgedrag van ouders ten aanzien van roken en drinken}

De Sociaal Cognitieve Leertheorie van Bandura (Bandura, I977) stelt dat ouders een rolmodel zijn voor hun kinderen. Kinderen observeren gedragingen van hun ouders en vervolgens kopiëren zij deze als zij zich in eenzelfde situatie bevinden. Ook dragen ouders met hun eigen rook- en drinkgedrag hun normen over roken en drinken uit. Op basis van de Sociaal Cognitieve Leertheorie is in veel studies de relatie tussen het rooken drinkgedrag van ouders en het roken en drinken van alcohol van jongeren onderzocht. Voor zowel roken als alcoholgebruik kan geconcludeerd worden dat het voorbeeldgedrag van ouders een aanhoudend effect heeft tijdens de adolescentie. Kinderen waarvan beide ouders roken hebben vier keer zoveel kans om zelf met roken te beginnen dan kinderen van wie de ouders nooit hebben gerookt. Slechts een paar studies hebben gekeken naar de invloed van rokende moeders en vaders apart. Het lijkt dat er weinig verschil is tussen de invloed van rokende vaders en moeders op het rookgedrag van hun kind (Harakeh e.a., 20I0). Stoppen met roken lijkt zinvol te zijn voor rokende ouders. Hoe eerder ouders in het leven van hun kinderen stoppen met roken, hoe kleiner de kans dat kinderen in de adolescentie beginnen met roken. Voor ouders die dit niet kunnen of willen, is het belangrijk dat zij zo min mogelijk roken in de aanwezigheid van het kind.

Het voorbeeldgedrag van ouders lijkt ook van invloed op het alcoholgebruik van jongeren; naarmate ouders meer alcohol drinken, is de kans groter dat kinderen veel gaan drinken en op jonge leeftijd beginnen met drinken. Anders dan bij roken zijn er bij alcoholgebruik wel verschillen gevonden tussen de invloed van het alcoholgebruik van vaders en van moeders. De studies die het alcoholgebruik van ouders apart hebben 
onderzocht, suggereren dat de invloed van drinkende vaders sterker is dan van drinkende moeders (Van der Vorst e.a., 2009). Een mogelijke verklaring is dat vaders meer alcohol drinken dan moeders en dat vaker in het bijzijn van hun kinderen doen (Verdurmen e.a., 2008).

Daarnaast blijken rokende ouders minder vaak rookspecifieke opvoeding toe te passen dan niet rokende ouders (Den Exter Blokland e.a., 2006; Harakeh e.a., 2005). Hetzelfde geldt voor ouders die veel of regelmatig alcohol drinken (Van der Vorst e.a., 2005; Verdurmen e.a., 2008). Toch heeft het voor rokende en drinkende ouders wel degelijk zin om een rook- en alcoholspecifieke opvoeding te hanteren. Het stellen van regels ten aanzien van het alcoholgebruik van het kind is bij stevig drinkende ouders even effectief als bij niet-drinkende ouders (Van der Vorst e.a., 2005).

\section{Beschikbaarheid van sigaretten en alcohol thuis}

Beschikbaarheid van sigaretten en alcoholische drank thuis lijkt een risicofactor voor roken en drinken door adolescenten. Er bestaat een positief verband tussen de beschikbaarheid van alcohol thuis en het alcoholgebruik van jongeren. Twee recente longitudinale studies laten zien dat de beschikbaarheid van alcohol thuis gerelateerd is aan een toename van alcoholgebruik onder jongeren van twaalf tot en met i 6 jaar (Komro, Maldonado-Molina, Tobler, Bonds, \& Muller, 2008; Van den Eijnden e.a., 20I0). Het laatste onderzoek suggereert zelfs dat beschikbaarheid van alcohol een sterkere voorspeller is van alcoholgebruik van het kind, dan het alcoholgebruik van de ouders.

De invloed van de beschikbaarheid van sigaretten thuis, blijkt minder duidelijk uit onderzoek. Den Exter Blokland en collega's (2006) zagen in hun longitudinale studie geen duidelijke invloed van de beschikbaarheid van sigaretten op het beginnen met roken. Mogelijk is de beschikbaarheid van sigaretten wel gerelateerd aan het al dan niet doorgaan met roken (Den Exter Blokland e.a., 2006).

\section{Preventie}

Rook- en alcoholspecifieke opvoeding blijken van belang te zijn voor het uitstellen en verminderen van roken en alcoholgebruik van adolescenten. Op basis van het bovenstaande zouden ouders zo min mogelijk in het bijzijn van hun kinderen moeten roken of drinken, zouden ze een anti-rook- en -alcoholnorm moeten uitdragen en zo af en toe een constructief gesprek moeten voeren over alcoholgebruik en roken. Voor alcoholgebruik geldt daarbij eveneens dat ouders het drinken van alcohol door hun kinderen zouden moeten verbieden en de beschikbaarheid van alcohol zouden moeten beperken. Kortom, er kan geconcludeerd worden dat het belangrijk is om kennis over rooken alcoholspecifieke opvoeding van ouders toe te passen in preventieprojecten. De vraag is echter of deze adviezen in de huidige gezinsgerichte preventieprogramma's (waarvan de effecten wetenschappelijk zijn onderzocht) voor roken en alcoholgebruik terug te vinden zijn. Als dat niet zo is, dan zou dit immers betekenen dat er door preventieprogramma's meer gezondheidswinst te behalen is dan op dit moment het geval is. 


\section{Gezinsgerichte interventies en rook- en alcoholspecifieke opvoeding}

Ondanks dat men de noodzaak van wetenschappelijke effectiviteitstudies inziet, is er in Nederland nog nauwelijks onderzoek gedaan naar gezinsgerichte interventies voor alcoholgebruik en/of roken (Cuijpers, Scholten, \& Conijn, 2006) met uitzondering van de effectiviteitsstudie naar een alcoholinterventie van Koning en anderen (2009). We baseren ons daarom in dit artikel vooral op buitenlandse effectiviteitstudies van dergelijke interventies, voornamelijk studies uit de V.S. Er wordt in de bestaande gezinsgerichte interventies vooral gefocust op algemene opvoedtechnieken waarvan de relevantie empirisch is bewezen, zoals het houden van toezicht/discipline, het bieden van steun, de gezinscohesie vergroten en helpen bij emoties reguleren (zie bijvoorbeeld het Iowa Strengthening Families Program (ISFP), Spoth, Redmond, \& Lepper, I999). Voor rook- en alcoholspecifieke opvoeding is slechts beperkte aandacht in de huidige gezinsgerichte interventies (zie Cuijpers e.a., 2006 of Smit e.a., 2008 voor een samenvatting van de inhoud van gezinsgerichte interventies). Daarnaast blijken de rook- en alcoholspecifieke opvoedingsadviezen die hierin worden gegeven, slechts in beperkte mate op wetenschappelijke literatuur gebaseerd te zijn (o.a. Bauman e.a., 2002 (Family Matters); Werch e.a., 2003). In veel preventieprojecten worden ouders bijvoorbeeld communicatievaardigheden aangeleerd al dan niet met alcohol of roken als onderwerp. Zo krijgen ouders in het Start Taking Alcohol Risks Seriously (sTARs; Werch e.a., 2003) voor een bepaalde tijd elke week 2 ansichtkaarten thuisgestuurd met een alcoholboodschap erop, bijvoorbeeld 'Zeg tegen je kind dat je heel boos zult worden als hij/zij alcohol drinkt', ondanks het feit dat een dergelijke boodschap niet met het alcoholgebruik van jongeren samenhangt (Van der Vorst e.a., 2005) en het de vraag is of deze boodschap constructief is. Een genuanceerder advies aan ouders lijkt een betere strategie; bijvoorbeeld benadrukken dat een goed gesprek over alcoholgebruik, waarbij de jongere zich comfortabel en serieus genomen voelt, een beschermende werking kan hebben. Daarnaast worden ouders aangemoedigd om met hun kinderen vaker over alcohol of roken te praten (o.a. Stevens e.a., 2002), terwijl regelmatig over roken en alcohol praten ook averechtse effecten kan veroorzaken. Ouders zouden juist daarom op de hoogte dienen te worden gesteld van het feit dat veelvuldige ongemakkelijke gesprekken over roken en alcoholgebruik (bijv. gesprekken die irritatie oproepen of waarbij het kind zich terugtrekt) af te raden zijn.

Opvallend is dat het verminderen van eigen middelengebruik van ouders (interventies voor verslaafden niet meegerekend) nauwelijks aan bod lijkt te komen in preventieprojecten. De interventies lijken toch vooral gericht op het verbeteren van de ouder-kindrelatie en niet op datgene wat ouders thuis kunnen doen om het rookgedrag en alcoholgebruik van hun kinderen te beperken. Naar onze mening zouden gezinsgerichte interventies in ieder geval ook moeten inspelen op het eigen gebruik van ouders. Dit enerzijds omdat ouders belangrijke rolmodellen voor hun kinderen zijn en anderzijds omdat drinkende en rokende ouders minder geneigd zijn om alcoholspecifieke opvoeding (bijv. het stellen van regels) toe te passen (Verdurmen e.a., 2008). Een mooi voorbeeld van een interventie die wel inspeelt op het eigen gebruik (roken) van ouders is het Smoke Free Kids program (Jackson \& Dickinson, 2006). De resultaten van dit Amerikaanse programma zijn veelbelovend. Op dit moment wordt deze interventie ook in Nederland uitgevoerd en wordt de effectiviteit ervan getoetst (Hiemstra e.a., 2009). 


\section{Conclusie}

Gezinsgerichte interventies en rook- en alcoholspecifieke opvoeding kunnen het roken en alcoholgebruik van jongeren uitstellen en verminderen. Het Nederlandse Preventieproject Alcoholgebruik Scholieren (PAS) blijkt (het meest) effectief te zijn in het reduceren van alcoholgebruik onder middelbare scholieren, als zowel adolescenten als ouders een programma over alcoholgebruik wordt aangeboden (Koning e.a., 2009). Hoewel gezinsinterventies grotere effecten laten zien dan kindgerichte interventies, zijn de effecten van bestaande (veelal Amerikaanse) gezinsinterventies doorgaans klein (Smit e.a., 2008). Omdat deze gezinsgerichte projecten over het algemeen effectief blijken te zijn, zou men kunnen suggereren dat het opnemen van meer rook- en alcoholspecifieke opvoedingsadviezen minder belangrijk is. Het is echter goed mogelijk dat als de inzichten uit de rook- en alcoholspecifieke opvoedingsliteratuur toegepast worden in de programma's, dit tot grotere effecten op alcoholgebruik en roken zou leiden en dientengevolge tot minder gezondheidsrisico's voor jongeren en minder kosten voor de maatschappij. Ter illustratie, in verscheidene programma's wordt niet gesproken over het verbieden van alcohol. Ouders wordt geleerd hoe ze conflicten met hun kinderen kunnen vermijden, hoe ze hun kinderen autonomie kunnen geven en hoe ze open met hun kinderen kunnen communiceren (Thompson, Pomeroy, \& Gober, 2005). Dergelijke adviezen gelden inderdaad voor een algemene gezonde puberteitsontwikkeling, maar uitgaande van een positief opvoedingsklimaat lijkt specifiek voor de preventie van alcoholgebruik het tegenovergestelde van belang: verbieden van alcohol stelt het eerste glas alcohol uit en vermindert de toename in alcoholgebruik gedurende de adolescentie (o.a. Jackson e.a., I999; Van der Vorst e.a., 2009). Het lijkt daarom een gemiste kans voor de preventie van alcoholgebruik en alcoholgerelateerde problemen bij jongeren als men ouders dergelijke alcoholspecifieke opvoedingsstrategieën niet aanleert. Wij zouden dan ook willen adviseren om effectieve rook- en alcoholspecifieke opvoedingsstrategieën beter te integreren in bestaande gezinsinterventies.

Kortom, geconcludeerd kan worden dat ouders baat kunnen hebben bij gezinsgerichte interventies om het roken en alcoholgebruik van hun kinderen uit te stellen of te verminderen. Tegelijkertijd is er waarschijnlijk nog meer gezondheidswinst te behalen door nieuwe inzichten op het gebied van rook- en alcoholspecifieke opvoeding op te nemen in bestaande gezinsinterventies. Tot slot is het belangrijk om verder onderzoek te blijven doen naar de effectiviteit van rook- en alcoholspecifieke opvoeding.

\section{Literatuur}

Bahr, S. J., Hoffmann, J. P., \& Yang, X. (2005). Parental and peer influences on the risk of adolescent drug use. The Journal of Primary Prevention, 26, 529-55I.

Bandura, A. (I977). Social learning theory. Englewood Cliffs, NJ: Prentice-Hall.

Bauman, K. E., Ennett, S. T., Foshee, V. A., Pemberton, M., King, T. S., \& Koch, G. G. (2002). Influence of a family program on adolescent smoking and drinking prevalence. Prevention Science, 3, 35-42.

Chassin, L., Presson, C. C., Todd, M., Rose, J. S., \& Sherman, S. J. (I998). Maternal socialization of adolescent 
smoking: The intergenerational transmission of parenting and smoking. Developmental Psychology, 34, II89-I20I.

Cuijpers, P., Scholten, M., \& Conijn, B. (2006). Verslavingspreventie. Een overzichtsstudie. Den Haag: ZonMw Programma Verslaving.

De Leeuw, R. N. H., Scholte, R. H. J., Harakeh, Z., Van Leeuwe, J. F. J., \& Engels, R. C. M. E. (2008). Parental Smoking-specific communication, adolescents' smoking behavior and friendship selection. Journal of Youth and Adolescence, 37, I229-I24I.

Den Exter Blokland, E. A. W., Hale, W. W., III, Meeus, W., \& Engels, R. C. M. E. (2006). Parental antismoking socialization: Associations between parental anti-smokingsocialization practices and early adolescent smoking initiation. European AddictionResearch, 12, 25-32.

Engels, R. C. M. E., \& Willemsen, M. (2004). Communication about smoking in Dutch families: Associations between anti-smoking socialization and adolescent smoking-related cognitions. Health Education Research, $19,227-238$.

Harakeh, Z., Engels, R. C. M. E., Den Exter Blokland, E., Scholte, R. H. J., \& Vermulst, A. A. (2009). Parental communication appears not to be an effective strategy to reduce smoking in a sample of Dutch adolescents. Psychology and Health, 24, 823-84I.

Harakeh, Z., Scholte, R. H. J., De Vries, H., \& Engels, R. C. M. E. (2005). Parental rulesand communication: Their association with adolescent smoking. Addiction, 100, 862-870.

Harakeh, Z., Scholte, R. H. J., Vermulst, A. A., De Vries, H., \& Engels, R. C. M. E. (20I0). The Relations Between Parents' Smoking, General Parenting, Parental Smoking Communication, and Adolescents' Smoking. Journal of Research on Adolescence, 20, I40-165.

Hiemstra, M., Ringlever, L., Otten, R., Jackson, C., Van Schayck, O. C. P., \& Engels, R. C. M. E. (2009). Efficacy of smoking prevention program 'Smoke-free Kids': study protocol of a randomized controlled trial. BMC Public Health, 9, 477 .

Huver, R. M. E., Engels, R. C. M. E., \& de Vries, H. (2006). Are anti-smoking parenting practices related to adolescent smoking cognitions and behavior? Health Education Research, 21, 66-77.

Jackson, C., \& Dickinson, D. (2006). Enabling parents who smoke to prevent their children from initiating smoking. Archives of Pediatrics on Adolescent Medicine, 160, 56-62.

Jackson, C., Henriksen, L., \& Dickinson, D. (I999). Alcohol-specific socialization,parenting behaviors and alcohol use by children. Journal of Studies on Alcohol, 60 (3), 362-367.

Koning I. M., Vollebergh W. A. M., Smit, F., Verdurmen J. E. E., Van Den Eijnden R. J. J. M., Ter Bogt T. F. M., Stattin, H., \& Engels, R. C. M. E. (2009). Preventing heavy alcohol use in adolescents (PAS): cluster randomized trial of a parent and student intervention offered separately and simultaneously. Addiction, 104, I669-I678.

Komro, K. A., Maldonado-Molina, M. M., Tobler, A. L., Bonds, J. R., \& Muller, K. E. (2008). Effects of home access and availability of alcohol on young adolescents' alcohol use. Addiction, 102, I597-I680.

Kumpfer, K. L., Alvarado, R., \& Whiteside, H. O. (2003). Family-based interventions for substance use and misuse prevention. Substance Use Misuse, 38, I759-I787.

Smit, E., Verdurmen, J., Monshouwer, K., \& Smit, F. (2008). Family interventions and their effect on adolescent alcohol use in general populations; a meta-analysis of randomized controlled trials. Drug and Alcohol Dependence, 97, 195-206.

Spoth, R., Redmond, C., \& Lepper, H. (I999). Alcohol initiation outcomes of universal family-focused preventive interventions: one- and two-year followups of a controlled study. Journal of Studies on Alcohol, supplement 13, I03-III.

Stevens, M. M., Olson, A. L., Gaffney, C. A., Tosteson, T. D., Mott, L. A., \& Starr, P. (2002). A pediatric, 
practice-based, randomized trial of drinking and smoking prevention and bicycle helmet, gun, and seatbelt safety promotion. Pediatrics, 109, 490-497.

Thompson, S. J., Pomeroy, E. C., \& Gober, K. (2005). Family based treatment models targeting substance use and high risk behaviors among adolescents: A review. Journal of Evidence-based Social Work, 2, 207-233.

Van den Eijnden, R. J. J. M., Vet, R., Vermulst, A., \& Van de Mheen, D. (2010). The impact of alcohol-specific parenting practices on adolescents' alcohol use and alcohol-related problems. Resubmitted.

Van der Vorst, H., Burk, W. J., \& Engels, R. C. M. E (in druk). The role of parental alcohol-specific communication in early adolescents' alcohol use. Drug and Alcohol Dependence.

Van der Vorst, H., Engels, R. C. M. E., Deković, M., Meeus, W., \& Vermulst A. (2007). Alcohol-specific rules, personality and adolescents' alcohol use: A longitudinal person-environment study. Addiction, 102, I0641075 .

Van der Vorst, H., Engels, R. C. M. E., Meeus, W., Dekovic, M., \& Van Leeuwe, J. (2005). The role of alcoholspecific socialization in adolescents' drinking behaviour. Addiction, 100 (IO), I464-I476.

Van der Vorst, H., Vermulst, A. A., Meeus, W., Deković, M., \& Engels, R. C. M. E. (2009) Identification and prediction of drinking trajectories in early and mid-adolescence. Journal of Clinical Child and Adolescent Psychology, 38, 329-34I.

Verdurmen, J., Smit, E., Van Dorsselaer, S., Monshouwer, K., \& Schulten, I. (2008). Ouders over alcohol-, roken- en drugspecifieke opvoeding 2007. Kerngegevens uit het Peilstationsonderzoek Ouders. Utrecht: Trimbosinstituut.

Werch, C. E., Owen, D. M., Carlson, J. M., DiClemente, C. C., Edgemon, P., \& Moore, M. (2003). One-year follow-up results of the sTARs for families alcohol prevention program. Health Education Research, 18, 74-87. 